\section{X-ray health and safety}

David Blow, Professor of Biophysics at Imperial College, London, offers his opinion

X-RAY crystallography provides a tool for almost every branch of science and technology. Its applications extend from the routine analysis of purity and texture of manufactured products, through the identification of unknown substances and the detection of small amounts of impurities in materials of all kinds, to fundamental investigations of physical, chemical and biological importance. This means that X-ray diffraction apparatus is in use in a great many university departments, and in much of industry.

In the UK, under the Health and Safety at Work Act 1974, all these activities will be covered by new provisions which are being drafted by the Health and Safety Executive (HSE). For a large range of routine diffraction work, especially when a closed camera is used, such as a powder camera, the modifications to existing practice will be fairly simple. But for a substantial group of research workers, they present serious problems.

One may raise three principal objections. The first is that the regulations are being proposed without regard to the level of risk. There are no records of deaths from radiation accidents involving crystallographic apparatus. There is epidemiological evidence that exposure to ionising radiation shortens life, and increases the incidence of cancer. An important contribution to this evidence comes from studies on radiologists, who early in this century were not sufficiently careful to avoid exposure. But I am not aware that any evidence has been obtained from X-ray crystallography, where considerable effort has been made to reduce background radiation to a negligible level.

The only records of identifiable injury following misuse of crystallographic equipment in the UK are of burns causing blisters (usually to the hands), or a general reddening of the skin. The incidence of blistering burns has been estimated as one per 1,000 X-ray generator-years; nonblistering burns are three or four times more common. At Imperial College, where $70 \mathrm{X}$-ray beams are currently in use, one serious burn has occurred in the last 23 years.

The price of modifications to satisfy the regulations on new X-ray apparatus wil laverage $£ 500-£ 1,000$ per generator (with a much greater expense when additional generators are needed to minimise the problems of using one generator for several heams, or where more space is needed). Transitional costs in bringing existing X-ray equipment up to standard may be more. If the incidence of accidents is reduced to zero, an assumed lifetime of 10 years for a generator leads to an expenditure of $£ 50,000$ to $£ 100,000$ for each blistering burn which is avoided.

The second objection is that the rules have to apply equally to everybody. There is no allowance for the knowledge and experience which the professional has obtained. The law, we are told, must apply equally to all; but this principle does not apply in other contexts. Work with pathogens, or even work with inflammable substances, involves special risks which training and experience can minimise. A highly trained crystallographer may resent being forced to work in a foolproof but inconvenient fashion. There is a real danger, if the rules seem too restrictive, that crystallographers experienced enough to know the risks may indulge in some form of evasion.

The new provisions will rely heavily on an individual called the "Radiation Protection Adviser", who needs to define a scheme of work which provides a practicable method of prosecuting research, while maintaining the necessary safety standards. He must be prepared to do battle on both sides, to maintain techniques which are safe, but to limit costs and physical complexities to a level where research may proceed without impediment. An adviser who pursues a rigid line may eliminate accidents, but will eliminate progress as well; an adviser who is inventive, and who understands the problems on both sides, may save tens of thousands of pounds - or several years-by devising better procedures and better equipment.

One anticipates a severe shortage of suitably qualified Radiation Protection Advisers, for whom there is no course of training except bitter experience. In most factories there is no comparable adviser at present. The absence of suitable advisers may represent the biggest threat to research.

No one will object to the provision of improved mechanical and electrical equipment to reduce the risk of an accident. The only worry for standard equipment is the question of cost, and its effect on the value of crystallographic work, especially if the cost is far out of proportion to the level of risk. Much more serious problems are raised for those crystallographers who deal with unconventional apparatus, especially equipment involving small apertures and monochromatising crystals which involve continual realignment, or which require constant rearrangement of components. They may feel that these regulations will make their work extremely difficult, if not impossible.

The interlocks, barriers and inconvenient schemes of work proposed in the regulations may considerably complicate the introduction of novel equipment. In a case where physical interlocks are impracticable one might, for example, have to initial each item of a long check-list on each occasion before opening the shutter. Whatever happens, work will become more cumbersome, and a complicated administrative overhead of certification and inspection will be added to the difficulties of research.

The impact on work with non-standard equipment will depend crucially on the interpretations of the law and of regulations and codes of practice. Provisions drawn up by HSE depend on an interpretation of the law. It is hard to see how that interpretation could be challenged, except to wait for regulations to be brought into effect and then to test them, if necessary, in the courts. Radiation Protection Advisers will play a crucial role in any test of the new rules.

This is apparently the first time that consultation with experts outside HSE has been attempted before regulations were drawn up. This was done informally, and the main learned societies which deal with X-ray crystallography were not approached. On the initiative of individual scientists assisting in the drafting, a very valuable meeting of the Institute of Physics was organised last summer (12 July, 1977). This was the first occasion when most crystallographers heard of the proposed regulations. Such preliminary, informal consultations are probably far more effective than "formal" ones, but definite channels for consultation with learned societies need to be established.

HSE officials, now formulating regulations, can hardly be criticised for they have a duty to produce regulations consistent with the health and safety act and with the EEC agreement known as the Euratom Directive. And they can point to the flexibility of British certification procedures. Nevertheless, a period of some months is allowed for comments to be made to the Secretary of State, after which the provisions, modified as necessary in the light of comments received, will be laid before Parliament. It is essential that diffraction workers who have views about the proposals should make good use of this period for formal consultation, involving their professional institutions and learned societies. I believe there will still be room for improvement within the legal constraints. In particular, I would like to see explicit provision for "open beam areas", where research of certain kinds could continue with the uncomplicated and safe methods which are used today. 